This is the final peer-reviewed accepted manuscript of:

J.H. Nazzi Ehms, R. De Césaro Oliveski, L.A. Oliveira Rocha, C. Biserni

"Theoretical and numerical analysis on phase change materials (PCM): A case study of the solidification process of erythritol in spheres"

In: International Journal of Heat and Mass Transfer, Volume 119, 2018, Pages 523-532

The final published version is available online at:

https://doi.org/10.1016/i.ijheatmasstransfer.2017.11.124

Rights / License:

The terms and conditions for the reuse of this version of the manuscript are specified in the publishing policy. For all terms of use and more information see the publisher's website.

This item was downloaded from IRIS Università di Bologna (https://cris.unibo.it/)

When citing, please refer to the published version. 


\title{
THEORETICAL AND NUMERICAL ANALYSIS \\ ON PHASE CHANGE MATERIALS (PCM): A CASE STUDY OF THE SOLIDIFICATION PROCESS OF ERYTHRITOL IN SPHERES
}

\author{
J. H. Nazzi Ehms ${ }^{1}$, R. De Césaro Oliveski ${ }^{1}$, L. A. Oliveira Rocha ${ }^{1}$ and C. Biserni ${ }^{2}$ \\ ${ }^{1}$ Mechanical Engineering Graduate Program, Universidade do Vale do Rio dos Sinos, \\ 93022-750, São Leopoldo, Brazil. \\ ${ }^{2}$ Dipartimento di Ingegneria Industriale, Università degli Studi di Bologna, Viale \\ Risorgimento 2, 40136 Bologna, Italy.
}

\begin{abstract}
Phase change materials (PCM) present great potential for energy efficiency gains in thermal systems by storing solar energy or waste heat in industrial processes. This is due to the great amount of energy stored per mass unit within a small temperature range. In this paper we focus, by means of the numerical investigation, on the solidification process of the PCM erythritol in spheres, having 10, 20, 30 and $40 \mathrm{~mm}$ diameter, under wall temperatures of 10 , $15,20,25,30$ and $40 \mathrm{~K}$ below the phase change temperature of the material. The problem is considered two-dimensional in geometry and transient in time. The numerical model here adopted consists of mass, momentum, energy and volume fraction equations. The results have been initially validated by comparison with data found in literature. Afterwards, analysis of the convective streams on the liquid PCM, liquid fraction, heat flux in the sphere wall and total solidification times have been widely illustrated. The liquid fraction suffers a sharp reduction at the beginning of the solidification process due to the high heat flux at the initial times. As the solid layer adjacent to the shell increases, it causes an augmentation of thermal resistance, significantly reducing the heat flux. The shape of the curve representing the solid fraction shows similarity with the S-curve pattern of solidification. The total solidification time proved to be dependent on both the diameter length and the temperature difference $\Delta \mathrm{T}$ (between phase change material and wall temperature), being its influence reduced for lower temperature values. Finally, the liquid
\end{abstract}


fraction results, as a function of Fourier and Stefan numbers, have been employed to amend a dimensionless correlation found in literature.

Keywords: Phase Change Materials (PCM), Computational Fluid Dynamics (CFD) Solidification Process, Erythritol in Spheres, Convective Motions, Heat Flux, S-curve

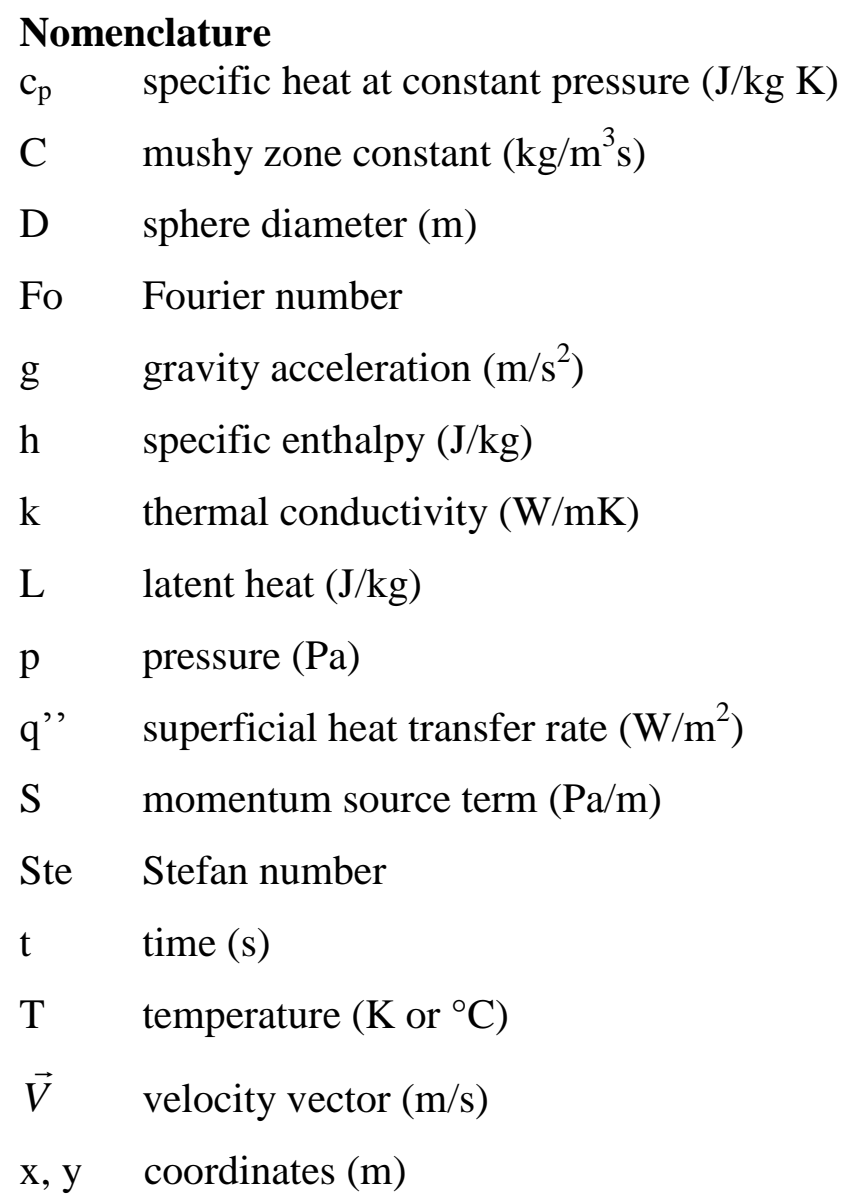

\section{Greek symbols}

$\alpha_{\mathrm{n}} \quad$ volume fraction

$\beta \quad$ liquid fraction

$\varepsilon \quad$ numerical value (to avoid division by 0 in eq. 4)

$\mu \quad$ dynamic viscosity $(\mathrm{kg} / \mathrm{ms})$

$\rho \quad$ density $\left(\mathrm{kg} / \mathrm{m}^{3}\right)$ 


\section{Subscripts}

$\begin{array}{ll}\text { a } & \text { average } \\ 1 & \text { liquidus } \\ \text { le } & \text { latent enthalpy } \\ \text { ref } & \text { reference value } \\ \text { s } & \text { solidus } \\ \text { se } & \text { sensible enthalpy } \\ \text { w } & \text { wall }\end{array}$

\section{Introduction}

Thermal energy storage has great importance for energy peak attenuation and energy supply during low availability periods. The main forms of thermal energy storage currently used are sensible and latent heat. The latter presents a greater advantage as it has the possibility of storing large amounts of energy per mass unit within a small temperature range. Materials that store latent heat, i.e. phase change materials (PCM) can be applied to many fields [1], i.e. solar thermal energy, refrigeration, food temperature conservation, medical applications, storage in concentrating solar power plants and heat recovery in industrial processes. Thus, PCM demonstrated great potential for use, mainly from the point of view of energy efficiency, which has also obvious economic benefits.

The choice of a PCM for a specific application is defined, mainly, for its phase change temperature; most of the PCM actually studied have temperatures between 0 and $60{ }^{\circ} \mathrm{C}$ [2]. In this range of temperatures, heating ventilation air conditioning (HVAC) and solar energy are the main applications. Among the above mentioned studies of PCM with phase change temperature below $60{ }^{\circ} \mathrm{C}$, particular emphasis can be ascribed to the works of Assis et al. [3, 4] with RT27, Tan et al. [5] and Chan et al. [6] with n-octadecane. It is worth to mention that all these studies analyzed spherical domains.

Regarding different geometries than spherical domain, even in the field of low phase change temperature, the works of Katsman et al. [7], Schmueli et al. [8] and Dubovsky et al. [9] with vertical cylinders, and the works of Ye et al. [10] and Shatikian et al. [11] with 
rectangular cavities are fully noteworthy. The numerical study highlighted in Ref. [12] covers the melting of $5 \mathrm{PCMs}$ whose phase change temperatures vary from $4{ }^{\circ} \mathrm{C}$ (RT4) to $82{ }^{\circ} \mathrm{C}$ (RT82), in vertical cylinder. Al-Abidi et al. [13] analyzed experimentally a tubular configuration with RT82, both in solidification and in melting processes. Hosseinizadeh et al. in Ref. [14] investigated experimentally and numerically the melting of RT80 in rectangular cavities.

As for PCMs with phase change temperature between 100 and $200{ }^{\circ} \mathrm{C}$, very few reports have been published $[15,16]$ and even more rare are the studies on PCMs with phase change temperature exceeding $200{ }^{\circ} \mathrm{C}$. Archibold et al. for example analyzed the melting [17] and solidification [18] processes of sodium nitrate $\left(\mathrm{NaNO}_{3}\right)$, whose phase change temperature is $306.8^{\circ} \mathrm{C}$, in spherical geometry.

Nevertheless, the majority of the researches conducted so far is concentrated on phase change temperatures below $100{ }^{\circ} \mathrm{C}$. Thus, this work's aim is to study the solidification process of erythritol, whose phase change temperature $\left(118^{\circ} \mathrm{C}\right)$ is in the above mentioned "rarely explored zone" (100-200 $\left.{ }^{\circ} \mathrm{C}\right)$. The solidification process in spheres has been analyzed regarding the convective motions in the liquid, the liquid fraction, the heat flux and the total solidification time. The geometrical domain here explored is not dissimilar from the one illustrated in Ref. [19] (please see Fig. 6) in which constructal design [20-23] has been employed. The difference is that in the present work the solidification process is constrained into the spherical shell while Constructal theory manifests itself when the shape is free to morph, so that the final geometry associated to solidification springs out as dendritic.

\section{Problem Statement}

A packed bed system used for thermal energy storage with PCM consists in a reservoir filled with spheres containing PCM. The heat transfer fluid flows around the spheres, transferring heat to or from the spheres. As the PCM density changes between the solid and liquid phases, a certain amount of air is needed inside the spheres in order to absorb the volume variation and maintain the shell's integrity. The fluid between the spheres flows 
with a temperature gradient through the entire domain, and the temperature at a certain point slowly changes over time [24].

It is important to mention that some studies consider the whole packed bed or a section with several spheres in the domain (which better represents real applications of a PCM packed bed) using simplifications such as considering the packed bed as porous media [2527]. In these studies, as the focus is the flow around the spheres, the main simplifications are made on the PCM spheres instead of the fluid flow between the spheres. In the present work, as the focus is the PCM inside the sphere, we consider constant temperature around a single sphere, in order to simplify the model in the external flow. Both approaches in the model simplification (external flow or in the PCM) are usually done to reduce computation time.

\subsection{Physical Model}

The studied geometry, depicted in Fig. 1, is spherical; it is filled with $98.5 \%$ of PCM and $1.5 \%$ of air. In order to keep constant pressure, the upper part of the sphere is opened, allowing air to enter. The geometry is symmetrical in the vertical axis, making possible to model half of the sphere in two dimensions. The diameters (D) here analyzed are: 10, 20, 30 and $40 \mathrm{~mm}$. The PCM contained in the spheres is erythritol, whose phase change temperature is $391 \mathrm{~K}\left(118^{\circ} \mathrm{C}\right)$. The other properties, deduced from literature $[15,28,29]$, are shown in Table 1.

\begin{tabular}{lc}
\hline \multicolumn{1}{c}{ Property } & Value \\
\hline \hline Latent heat $-L$ & 339,000 \\
Density - $\rho$ & $1480(389 \mathrm{~K})-1300(413 \mathrm{~K})$ \\
Specific heat $-C_{p}$ & $1350(389 \mathrm{~K})-2740(413 \mathrm{~K})$ \\
Thermal conductivity $-k$ & $0.733(389 \mathrm{~K})-0.326(413 \mathrm{~K})$ \\
Dynamic viscosity $-\mu$ & $2.7749 \times 10^{-5} \mathrm{~T}^{2}-0.0231747 \mathrm{~T}+4.844$ \\
\hline \hline
\end{tabular}

Table 1 - Physical properties of erythritol. 
With reference to all the tested cases, air that enters the domain has the same temperature of spheres wall and atmospheric pressure $(101.3 \mathrm{kPa})$, with density $(\rho)$ varying with temperature the following dependence: $\rho=1.2 \times 10^{-5} T^{2}-0.001134 T+3.4978[3]$.

\subsection{Governing Equations and Boundary Conditions}

The mathematical model consists of the mass (1), momentum (2) and energy (3) equations:

$$
\frac{\partial \rho}{\partial t}+\nabla \cdot(\rho \vec{V})=0
$$

$\frac{\partial \rho \vec{V}}{\partial t}+\nabla \cdot(\rho \vec{V} \vec{V})=-\nabla p+\nabla(\mu \nabla \vec{V})+\rho g+S$

$$
\frac{\partial(\rho h)}{\partial t}+\nabla \cdot(\rho \vec{V} h)=\nabla \cdot(k \nabla T)
$$

The mathematical model here developed is based on the so called "enthalpy-porosity method", in coherence with the treatment highlighted in Ref. [30]. "The software used in the present work is Ansys Fluent 16.1, which uses this method as default. However, other efficient methods exist in the literature to model phase change processes, such as the heat capacity method showed in references [28] and [29], whose are based on specific heat and viscosity." In the "enthalpy-porosity method", the solid-liquid interface is treated as a porous zone, governed by the source term in the momentum equation:

$$
S=\frac{(1-\beta)^{2}}{\left(\beta^{3}+\varepsilon\right)} C \vec{V}
$$

where $\varepsilon$ is a numerical value (0.001) used to avoid division by zero, $\beta$ is the liquid fraction during the phase change and $C$ is the mushy zone constant, that indicates the velocity damping of the material until it reaches zero as it solidifies. The liquid fraction during the phase change is calculated by the following equation: 


$$
\beta=\left\{\begin{array}{ccc}
0 & \text { if } & T<T_{s} \\
1 & \text { if } & T>T_{l} \\
\frac{T-T_{s}}{T_{l}-T_{s}} & \text { if } & T_{s}<T<T_{l}
\end{array}\right\}
$$

where $T_{s}$ is the solidus temperature and $T_{l}$ is the liquidus temperature.

In the energy conservation equation, the total enthalpy is given by the sum of sensible enthalpy $\left(\mathrm{h}_{\mathrm{se}}\right)$ and the latent enthalpy $\left(\mathrm{h}_{\mathrm{le}}\right)$, defined by Equations (6) and (7), respectively:

$$
\begin{aligned}
& h_{s e}=h_{r e f}+\int_{T_{r e f}}^{T} C_{p} d T \\
& h_{l e}=\beta L
\end{aligned}
$$

where $h_{r e f}$ is the enthalpy at the reference temperature $\left(T_{r e f}=298.15 \mathrm{~K}\right)$.

As the model has different unmixed fluids, the volume of fluid model (VOF) has been employed. In this model, the volume fraction of the fluid in a computational cell is described by Equation (8):

$$
\frac{\partial \alpha_{n}}{\partial t}+\nabla\left(\alpha_{n} \vec{V}\right)=0
$$

where $\alpha_{n}$ is the volume fraction of the " $\mathrm{n}$ " fluid in the computational cell, whose value varies from 0 for the cell that doesn't contain this fluid to 1 for the cell filled with this fluid.

In all the analyzed cases, the initial temperature is $393 \mathrm{~K}$, with $T_{s}=389 \mathrm{~K}$ and $T_{l}=391$ K. For each diameter length $D$, we performed 6 runs of temperature differences $(\Delta T=10$, $15,20,25,30$ and $40 \mathrm{~K})$, between the wall temperature $\left(T_{w}\right)$ and the average phase change temperature $\left[T_{a}=\left(T_{s}+T_{l}\right) / 2\right]$. The sphere wall has no slip condition and the opening had a "Pressure outlet". In all the cases, we used $C=10^{8}$. 


\subsection{Numerical Modeling and Validation}

The numerical procedure was developed using the following methods: SIMPLE for pressure-velocity coupling, PRESTO for pressure discretization (Patankar [33]), Second Order Upwind for momentum discretization and Geo-Reconstruct for volume fraction (ANSYS [34]). Under-relaxation factors used were 0.4 for pressure, 0.2 for liquid fraction, 0.8 for energy and 0.5 for density, body forces and momentum. Convergence criteria were: $10^{-8}$ for energy equation and $10^{-5}$ for mass and velocity, with a maximum 1,000 iterations per time step $(d t)$.

Three spatial meshes and three time steps have been tested for $D=10 \mathrm{~mm}$, with $\Delta T=40 \mathrm{~K}$. This scenario was chosen because of the higher temperature gradient in the spatial distribution. The mesh sizes details are: 2,448, 3,918 and 5,942 rectangular elements. Figure 2, with particular reference to the detail of Figure 2(b), highlights that meshes have near-wall refinement.

Figures 3(a) and 3(b) report graphically the liquid fraction, $\beta$, as a function of time, $t$, varying the spatial grid size (Fig. 3(a)) and the time discretization (Fig. 3(b)). The results of Fig. 3(a) indicate that the grids are practically equivalent. Among these results, differences in $\beta$ agree within $1 \%$ until $99 \%$ of PCM solidifies $(\beta<0.01)$, even with the less refined grid (2,448 elements) needing most iterations to converge. Thus, we decided to adopt the intermediate grid (3,918 elements), because of less calculation time needed in relation to the more refined grid.

Three scenarios of time step verification have been illustrated in Figure 3(b), precisely $d t=0.01 ; 0.005$ and $0.002 \mathrm{~s}$. In quantitative terms, the above mentioned set of results agree within less than $1 \%$. However, sporadic convergence difficulties have been observed for $d t$ equal to $0.01 \mathrm{~s}$. Thus, we decided to adopt $d t=0.005 \mathrm{~s}$, due to the unnecessary increase in calculation time for the use of $d t=0.002 \mathrm{~s}$.

Numerical validation was performed by comparison with the numerical and experimental results of Assis et al. in Ref. [4], using RT27 as PCM, contained in a spherical shell with $D=40 \mathrm{~mm}$ and $\Delta T=20 \mathrm{~K}$. Figure 4 , in which the temporal variation of the liquid fraction has been reported, shows agreement between results over all the process evolution. Figure 4 also shows the solid fraction $(1-\beta)$ that makes easier to understand the 
S-shaped curves of solidification and melting processes described by [35-38]. Among the three stages of the $\mathrm{S}$ curve $[35,36]$, the first part of invasion is less visible, in the beginning of the solidification process, due to the short duration of this stage in comparison with the entire process. The stage of consolidation is clearly visible as the rapid increasing of the solid fraction, as well as the plateau stage takes place at the end of the process, when the thermal resistance in the solid portion of the PCM causes the decrease in the solidification rate.

Figures 5(a-c) present liquid fraction contours, for $t=5,10,15,20$ and 25 min, with reference to the present work, as well as the experimental and numerical results of Assis et al. [4], respectively. In these figures, it is possible to observe that thickness of PCM solid layer (shown in blue color) obviously increases over time, reducing the volume occupied by liquid (shown in red color). It is worth to mention that the same color scale will be used in similar results throughout this work. Based on pure observation, we confirm that the results of the present work (Fig. 5(a)) show good agreement with the experimental (Fig. 5(b)), and numerical results (Fig. 5(c)) of Assis et al. [4], matching the quantitative analysis.

\section{Results and Discussion}

\subsection{Convective Motions on Liquid PCM}

In Figures 6 (a-f) velocity streamlines in the region with liquid PCM (left part) and the temperature contours (right part) have been depicted for $D=30 \mathrm{~mm}, \Delta T=30 \mathrm{~K}$ and $\beta=$ $0.7 ; 0.5 ; 0.2 ; 0.1 ; 0.05$ and 0.01 , respectively. The greater velocities are observed in the

early stages, being rapidly reduced for values near $0.1 \mathrm{~mm} \mathrm{~s}^{-1}$ in $420 \mathrm{~s}$, corresponding to $\beta$ $=0.2$. The gradual reduction in liquid PCM velocity is obviously followed by the augmentation in solid layer thickness (shown in blue color), distancing the isothermal lines. Thus, isothermal lines move away, indicating a reduction in the wall temperature influence.

At the beginning of solidification process, the temperature difference between the cold sphere wall and the PCM induces a downflow circulation of liquid near the wall. Consequently, an upflow occurs in the vicinity of the center. Over time, solid layer thickness increases near the wall, with the solidification front in temperature approaching 
the liquid PCM temperature. Thus, temperature difference is too low to keep the initial velocity values, so that a gradual reduction in velocity occurs.

With the increase in the PCM solid layer thickness and consequent reduction in convective flows, the greater temperature difference is detected in the air-liquid PCM interface, i.e., in the upper part of the sphere. Thus, a second convective flow takes shape close to the sphere center, even if it results to be less intense that the one observed initially. Both exist simultaneously for a time interval. This second flow is observed for a shorter period, being reduced by the decrease in the contact area between air and liquid PCM, until it disappears with full solidification of the upper part of liquid PCM in contact with air.

The greater velocity values of liquid PCM are observed in the configurations with greater $D$ and $\Delta T$.

Figures $7(\mathrm{a}, \mathrm{b})$ highlight the velocity vectors scaled in magnitude with $t=0.5 \mathrm{~min}, D=$ $40 \mathrm{~mm}$ and $\Delta T=40 \mathrm{~K}$, for half the section and in detail near the solidification front. It is worth to mention that the upper region containing air is depicted in light grey, while the solid PCM near the wall is shown in dark grey. The greater velocities observed in this case are around $3.0 \mathrm{~mm} \mathrm{~s}^{-1}$ at $0.5 \mathrm{~min}$, in the region close to the solidification front, represented in detail in Fig. 7(b). After this initial period, the velocity field is rapidly reduced, reaching values around $1 \mathrm{~mm} \mathrm{~s}^{-1}$ at $2 \mathrm{~min}$ and $0.2 \mathrm{~mm} \mathrm{~s}^{-1}$ at $3 \mathrm{~min}$. As for the other cases, fixing $D$ and for smaller $\Delta T$ values, the velocities observed in early stages are inferior for smaller $\Delta T$. The influence of $D$ is even more pronounced, with smaller $\mathrm{D}$ producing velocities significantly smaller, as in the case of $D=20 \mathrm{~mm}$ with $\Delta T=40 \mathrm{~K}$, which at $t=0.5 \mathrm{~min}$, presents velocities smaller than $1 \mathrm{~mm} \mathrm{~s}^{-1}$.

\subsection{Liquid Fraction}

The liquid fraction is defined as the ratio between liquid mass over the total PCM mass, at a given moment. Thus, liquid fraction can be considered directly proportional to the amount of latent heat stored. The liquid fraction contours can be seen in Figures $8(\mathrm{a}-\mathrm{b})$, for $\Delta T=20 \mathrm{~K}$ in spheres with $D=10$ and $40 \mathrm{~mm}$, respectively. In the pictures, each column represents the approximate $\beta$ values of $0.5 ; 0.2 ; 0.05$ and 0.01 . In each row are shown the results relative to one diameter, making it possible to observe the gradual 
increase of the solid layer, from the wall towards the sphere center, thus reducing liquid fraction. Also it can be observed that for the same value of $\beta$, the contours referred to different diameters are virtually equal, even if the time necessary to reach a certain value of $\beta$ increases for greater diameters.

Figures 9 (a-d) illustrate the temporal variation of the liquid fraction, $\beta$, with reference to all the possible combinations of $\Delta T$ and $D$ here investigated, precisely $\Delta T=10,15,20$, 25,30 and $40 \mathrm{~K}$, and $D=10,20,30$ and $40 \mathrm{~mm}$, respectively. Based on pure observation, independently of $D$, the increase of $\Delta T$ reduces the time necessary to complete the solidification process. Moreover, and still independently of $D$, the curves for different $\Delta T$ present similar shapes, such as S-curves pattern described by Bejan et al. [35]. The principal difference results to be the time elapsed in the process, which increases proportionally to $D$, when comparing the same $\Delta T$ value. Still in relation to Figures 9 (a-d), we can notice that, in all the analyzed scenarios, the most evident characteristic is the fast solidification in the early stages, causing $\beta$ reach values below 0.5 in a short time. This time, obviously, depends directly on $D$ and inversely on $\Delta T$. For example, for $D=40 \mathrm{~mm}$ (Fig. 9(d)) and $\Delta T=10 \mathrm{~K}$, the time necessary to reach $\beta=0.5$ is 10 minutes. However, for the same $\Delta T$ and $\beta$, fixing $D=10 \mathrm{~mm}$ (Fig. 9(a)), the time changes to 0.67 minutes. This means that reducing $75 \%$ the value of $D$, it decreases approximately $93 \%$ of the solidification time. The same is not observed when $\Delta T$ increases and $D$ remains the same. For example, for $D=30 \mathrm{~mm}$ (Fig. 9(c)) and $\beta=0.5$, the time elapsed is, approximately, 1.5 minutes for $\Delta T=40 \mathrm{~K}$ and 5 minutes for $\Delta T=10 \mathrm{~K}$. This means, by reducing $75 \%$ of the value of $\Delta T$, the solidification time increases $233 \%$. Finally, to summarize, the outcome is that $D$ exerts greater influence.

\subsection{Total Solidification Time}

The total solidification time is defined as the time necessary for liquid fraction $\beta<0.01$. These times are shown in Fig. 10 as function of sphere diameters length $D$, varying $\Delta T$. We can observe that the solidification time increases significantly for the smaller $\Delta T$ and presents less variation in correspondence to the greater $\Delta T$. The influence of $\Delta T$ for smaller diameters is also reduced in comparison with the greater ones. In relation to 
$D$, it is possible to verify a direct and more pronounced proportionality, since $D$ influences directly the sphere volume.

\subsection{Wall Heat Flux in the Spheres}

The heat flux $(q ")$ in the sphere wall determines the energy (per unit surface) transferred to the exterior over time. The results of $q$ " vs. $t$ are shown in Figures 11(a-d), for $D=10,20,30$ and $40 \mathrm{~mm}$, respectively. The time axis are in logarithmic scales to facilitate visualization, since $q$ " suffers a sharp reduction in the early stages for all the cases analyzed. The greater $\Delta T$ provides superior values of $q$ " in the early stages, showing a more pronounced reduction over time. This makes the curves referred to the greater $\Delta T$ ( 40 , 30 and $25 \mathrm{~K}$ ) cross the others in the final stages of the process, as can be better observed in Fig. 11(a). It is also important to emphasize that spheres of different diameters with the same $\Delta T$ exhibit similar heat fluxes in the early stages, due to the same initial temperature condition. However, it is worth to mention that over time, the reduction of $q$ " is sharper for the smaller $D$. For example, fixing $\Delta T=40 \mathrm{~K}$ the value of $q$ " is approximately $25 \mathrm{~kW} \mathrm{~m}^{-2}$ for all $D$ in the early stages. However, for $t=4 \mathrm{~min}, q^{\prime \prime}=4.3 \mathrm{~kW} \mathrm{~m}^{-2}$ for $D=30 \mathrm{~mm}$ and $3.7 \mathrm{~kW} \mathrm{~m} \mathrm{~m}^{-2}$ for $D=20 \mathrm{~mm}$. The reduction of $q$ " over time can be intended as a consequence of the increase in the thermal resistance as a result of the augmentation in the PCM solid layer thickness. Thus, it is possible to deduce an interdependence between $q$ ", $\beta$ and the solid layer thickness. The reduction of $\beta$ means an increase in the solid layer thickness and, consequently, in the thermal resistance. The increase of the thermal resistance, in turn, reduces $q$ " for the exterior of the sphere.

In order to compare more properly the results for different sphere sizes, Fig. 12 shows the values of $q$ " as a function of $\beta$, for $\Delta T=10 \mathrm{~K}$, with $D=10,20,30$ and $40 \mathrm{~mm}$. The scale of $\beta$ in the abscissa axis is shown in descending order, so that the curves follow temporally the process. It is possible to observe that, for the same $\Delta T, q$ " referred to smaller spheres exceeds the other curves during the solidification process, even if for a certain time period. This increase of $q$ " is due to the smaller solid layer thickness for the smaller $D$, representing, in turn, smaller thermal resistances. 


\subsection{Dimensionless Correlation}

Assis et al. in Ref. [4] presented the following correlation for the liquid fraction in the process of PCM solidification in spheres:

$$
\beta=\left[1-(4.5 \text { FoSte })^{1 / 2}\right]^{2}
$$

where Fourier $(\mathrm{Fo})$ and Stefan $(\mathrm{Ste})$ numbers are defined as:

$$
\begin{aligned}
& F o=\left(\frac{k}{\rho C_{p}}\right)\left(\frac{t}{R^{2}}\right) \\
& \text { Ste }=\frac{C_{p} \Delta T}{L}
\end{aligned}
$$

Based on the numerical results obtained in the present work, we propone in Eq. 12 an emendation regarding the multiplication coefficient (from 4.5 to 3.8 ):

$$
\beta=\left[1-(3.8 \mathrm{FoSte})^{1 / 2}\right]^{2}
$$

Figure 13 shows the comparison between the numerical results of the present work in relation to those obtained through the original correlation of Assis et al. [4] (Eq. 9) and through the adjusted correlation (Eq. 12). We can observe that, throughout the entire domain, numerical results and the modified correlation do not present visible differences.

Furthermore, Figure 14 highlights the values of $\beta$ obtained numerically and through the correlation here amended. It is worth mentioning that, in order to facilitate visualization, the axes of the graph are inverted. It is possible to observe a great agreement throughout the process, including the final stages, where variations in the low values of $\beta$ can imply great differences, ensuring even more agreement with the modified correlation.

\section{Concluding Remarks}


In the present work, we implemented a numerical model for the solidification process of PCM in spheres, containing $98.5 \%$ of its volume initially filled with liquid and the remaining part with air. The model was validated satisfactorily by comparison with the data of Assis et al. illustrated in Ref. [4]. In sequence, we studied the solidification process of PCM erythritol in spheres with diameter $D=10,20,30$ and $40 \mathrm{~mm}$. For each $D$, several $\Delta T$ $(10,15,20,25,30$ and $40 \mathrm{~K})$ were simulated.

The presented results show the influence of $\Delta T$ and $D$ in the variation of the liquid fraction $\beta$ and the superficial heat flux $q$ " throughout the solidification process, as well as in the total solidification time. We observed similar tendencies for all the studied cases, with a greater variation of $\beta$ at the early stages, which is magnified by an increase of $\Delta T$.

The solidification rate decreases with the augmentation of the thermal resistance of the solid layer, which grows over time from the sphere wall. This fact is also shown by the variation of $q$ ", which suffers sharp reduction at the early stages. Still in relation to q", similar values were observed in the early stages for different $D$, but with the same $\Delta T$. However, its reduction over time was more intense for smaller $D$. With the increase of the solid PCM layer, we observed also the reduction of the convective streams in the liquid phase.

The total solidification time proved to be augmented by the decrease of $D$, while the increase of $\Delta T$ causes an inverse effect. It is still possible to confirm that the main influence is of $D$, as this defines the amount of PCM in the sphere and consequently the amount of energy stored.

Furthermore, a dimensionless correlation presented in literature [4] was tested with the liquid fraction results obtained in the present work. A coefficient emendation in the above mentioned correlation has been here proposed showing excellent agreement with the numerical results: it can be considered fully valid for the solidification process of erythritol in spheres in the range of diameter between 10 and $40 \mathrm{~mm}$ and $\Delta \mathrm{T}$ between 10 and $40 \mathrm{~K}$.

Finally, a cue of reflection in view of a possible future application of Constructal theory has been pointed out: solidification process can be a manifestation of Constructal Law once the domain in which PCM takes place is free to morph, according to the constructal principle of "optimal distribution of imperfections" [39]. The model used in the 
present work can also be improved in the future, considering closed sphere and including the external heat flux variation through correlation data of flow and heat transfer around a sphere. Thus, comparisons can be made with the constant temperature condition in order to evaluate the real accuracy of the model.

\section{Acknowledgements}

José Ehms and Prof. Rejane Oliveski acknowledge the financial support of FAPERGS, Porto Alegre, RS and CAPES, Brasília, DF, Brazil. Prof. Luiz Rocha's work was sponsored by CNPq, Brasília, DF, Brazil. Prof. Cesare Biserni was funded by the Italian Ministry for Education, University and Research.

\section{References}

[1] A. Sharma, V.V. Tyagi, C.R. Chen, D. Buddhi, Review on thermal energy storage with phase change materials and applications, Renewable and Sustainable Energy Reviews, 13, 318-345, 2009.

[2] F. Agyenim, N. Hewitt, P. Eames, M. Smyth, A review of materials, heat transfer and phase change problem formulation for latent heat thermal energy storage systems (LHTESS), Renewable and Sustainable Energy Reviews, 14, 615-628, 2010.

[3] E. Assis, L. Katsman, G. Ziskind, R. Letan, Numerical and experimental study of melting in a spherical shell, International Journal of Heat and Mass Transfer, 50, 17901804, 2007.

[4] E. Assis, G. Ziskind, R. Letan, Numerical and experimental study of solidification in a spherical shell, Journal of Heat Transfer, 131, 024502 1-024502 5, 2009.

[5] F.L. Tan, S.F. Hosseinizadeh, J.M. Khodadadi, L. Fan, Experimental and computational study of constrained melting of phase change materials (PCM) inside a spherical capsule, International Journal of Heat and Mass Transfer, 52, 3464-3472, 2009.

[6] C.W. Chan, F.L. Tan, Solidification inside a sphere - an experimental study, International Communications in Heat and Mass Transfer, 33, 335-341, 2006. 
[7] L. Katsman, V. Dubovsky, G. Ziskind, R. Letan, Experimental investigation of solidliquid phase change in cylindrical geometry, Proc. ASME-JSME Thermal Engineering Summer Heat Transfer Conference, Vancouver, Canada, 2007.

[8] H. Shmueli, G. Ziskind, R. Letan, Melting in a vertical cylindrical tube: Numerical investigation and comparison with experiments, International Journal of Heat and Mass Transfer, 53, 4082-4091, 2010.

[9] V. Dubovsky, E. Assis, E. Kochavi, G. Ziskind, R. Letan, Study of solidification in vertical cylindrical shells, Proc. 5th European Thermal-Sciences Conference, Netherlands, 2008.

[10] W. Ye, D. Zhu, N. Wang, Fluid flow and heat transfer in a latent thermal energy unit with different phase change material (PCM) cavity volume fractions, Applied Thermal Engineering, 42, 49-57, 2012.

[11] V. Shatikian, G. Ziskind, R. Letan, Numerical investigation of a PCM-based heat sink with internal fins, International Journal of Heat and Mass Transfer, 48, 3689-3706, 2005.

[12] J.J. Estrázulas, Estudo numérico da mudança de fase de PCMs em cavidades cilíndricas, Dissertação, Programa de Pós-Graduação em Engenharia Mecânica, Universidade do Vale do Rio dos Sinos (UNISINOS), São Leopoldo, Brasil, 2015.

[13] A.A. Al-Abidi, S. Mat, K. Sopian, M.Y. Sulaiman, A.T. Mohammad, Numerical Study of PCM solidification in a triplex tube heat exchanger with internal and external fins, International Journal of Heat and Mass Transfer, 61, 684-695, 2013.

[14] S.F. Hosseinizadeh, F.L. Tan, S.M. Moosania, Experimental and numerical studies on performance of PCM-based heat sink with different configurations of internal fins, Applied Thermal Engineering, 31, 3827-3838, 2011.

[15] F. Agyenim, P. Eames, M. Smyth, Heat transfer enhancement in medium temperature thermal energy storage system using a multitube heat transfer array, Renewable Energy, 35, 198-207, 2010.

[16] R.C. Oliveski, D. Del Col, Numerical Simulation of Thermal Energy Storage with PCM, Proc. Eurotherm Seminar Advances in Thermal Energy Storage, Lleida, Spain, 2014.

[17] A.R. Archibold, J. Gonzalez-Aguilar, M.M. Rahman, D.Y. Goswami, M. Romero, E.K. Stefanakos, The melting process of storage materials with relatively high phase 
change temperatures in partially filled spherical shells, Applied Energy, 116, 243-252, 2014.

[18] A.R. Archibold, M.M. Rahman, J. Gonzalez-Aguilar, D.Y. Goswami, E.K. Stefanakos, M. Romero, Phase change and heat transfer numerical analysis during solidification on an encapsulated phase change material, Energy Procedia, 57, 653-661, 2014.

[19] A. I. Ciobanas, A. Bejan, Y. Fautrelle, Dendritic solidification morphology viewed from the perspective of constructal theory, Journal of Physics D: Applied Physics, 39, 5252-5266, 2006.

[20] O.T. Olakoyejo, T. Bello-Ochende, J.P. Meyer, Constructal conjugate cooling channels with internal heat generation, Int. J. Heat Mass Transfer, 55, 4385-4396, 2012.

[21] H. Feng, L. Chen, Z. Xie, F. Sun, Constructal design for X-shaped hot water network over a rectangular area, Applied Thermal Eng., 87, 760-767, 2015.

[22] A. Bejan, Evolution in thermodynamics, Applied Physics Reviews, 4, 011305 1011305 19, 2017.

[23] A. Bejan, M. Alalaimi, A.S. Sabau, S. Lorente, Entrance-length dendritic plate heat exchangers, International Journal of Heat and Mass Transfer, 114, 1350-1356, 2017.

[24] A.F. Regin, S.C. Solanki, J.S. Saini, An analysis of a packed bed latent heat thermal energy storage system using PCM capsules: Numerical investigation. Renewable Energy, 34, 1765-1773, 2009.

[25] E. Oro, J. Chiu, V. Martin, L.F. Cabeza, Comparative study of diferente numerical models of packed bed thermal energy storage systems, Applied Thermal Engineering 50, 384-392, 2013.

[26] L. Xia, P. Zhang, R.Z. Wang, Numerical heat transfer analysis of the packed bed latent heat storage system based on an effective packed bed model, Energy, 35, 2022-2032, 2010. [27] A. Garcia, L.F. Cabeza, Numerical simulation of a PCM packed bed system: A review, Renewable and Sustainable Energy Reviews, 69, 1055-1063, 2017.

[28] M. Sillick, C.M. Gregson, Spray chill encapsulation of flavors within anhydrous erythritol crystals, LWT - Food Science and Technology, 48, 107-113, 2012.

[29] A. Hesaraki, CFD Modeling of Heat Charging Process in a Direct-contact Container for Mobilized Thermal Energy Storage, Mälarden University, Sweden, 2011. 
[30] A.D. Brent, V.R. Voller, Enthalpy-porosity technique for modeling convectiondiffusion phase change: Application to the melting of a pure metal, Numerical Heat Transfer, 13, 297-318, 1988.

[31] S. Lorente, A. Bejan, J.L. Niu, Phase change heat storage in an enclosure with vertical pipe in the center. International Journal of Heat and Mass Transfer, 72, 329-335, 2014.

[32] S. Lorente, A. Bejan, J. L. Niu, Constructal design of latent thermal energy storage with vertical spiral heaters, International Journal of Heat and Mass Transfer, 81, 283-288, 2015.

[33] S. V. Patankar, Numerical Heat Transfer and Fluid Flow, Hemisphere, Washington, DC. 1980.

[34] ANSYS Fluent Theory Guide, SAS IP, Inc, 2015.

[35] A. Bejan, S. Lorente, B. S. Yilbas, A. Z. Sahin, Why solidification has an S-shaped history, Scientific reports, 3, 2013.

[36] A. Bejan, The Physics of Life: the evolution of everything. St. Martin's Press, 2016

[37] A. Bejan, S. Ziaei, S. Lorente, The S curve of energy storage by melting, Journal of Applied Physics, 116, 114902, 2014.

[38] S. Ziaei, S. Lorente, A. Bejan, Morphing tree structures for latent thermal energy storage, Journal of Applied Physics, 117, 224901, 2015

[39] Bejan, A., Lorente, S., Design with Construtal Theory, Wiley, Hoboken, 2008. 


\section{FIGURES}

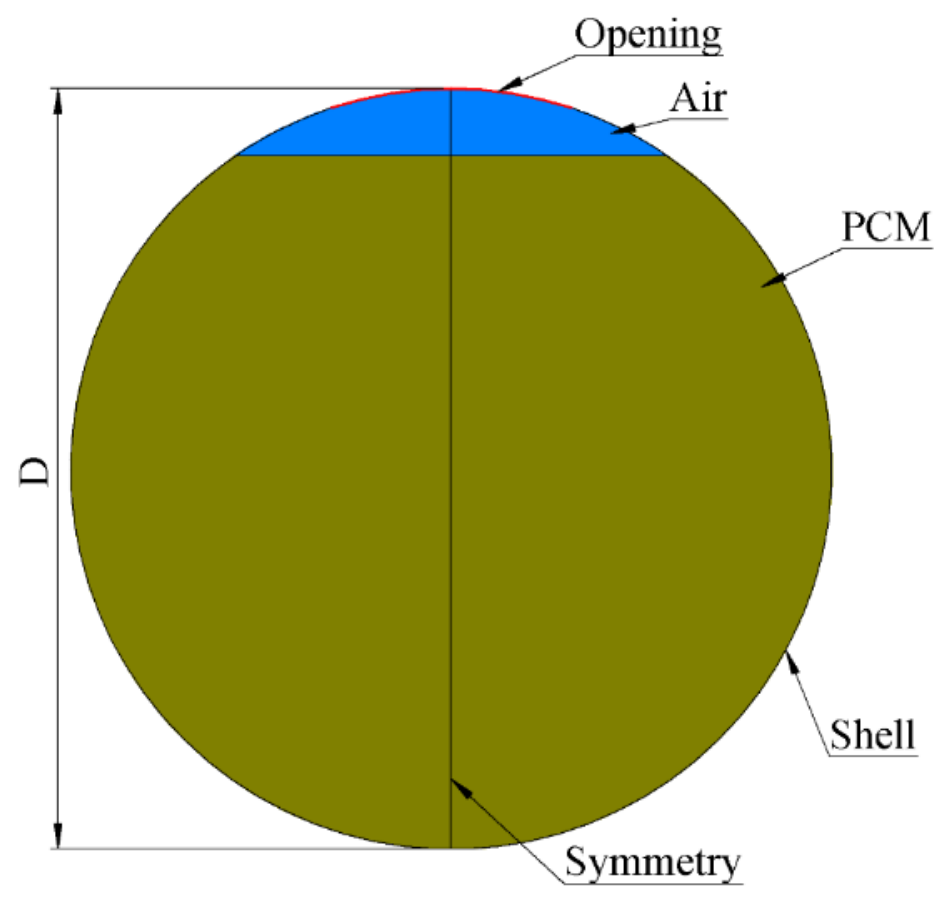

Figure 1 - Physical model. 


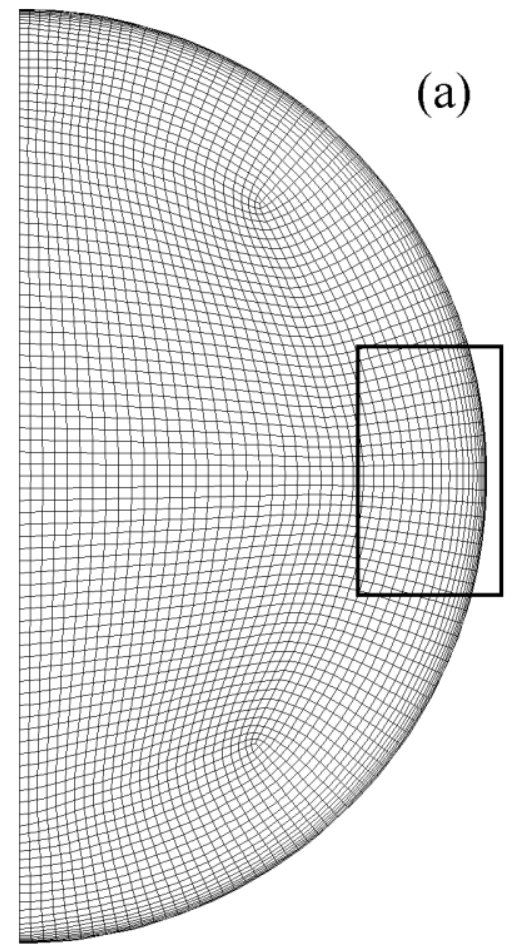

(b)

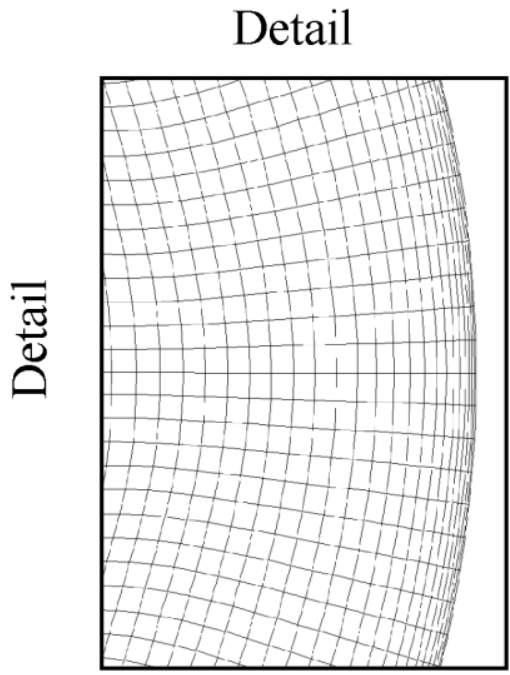

Figure 2 - Computational mesh: (a) integral and (b) detail. 

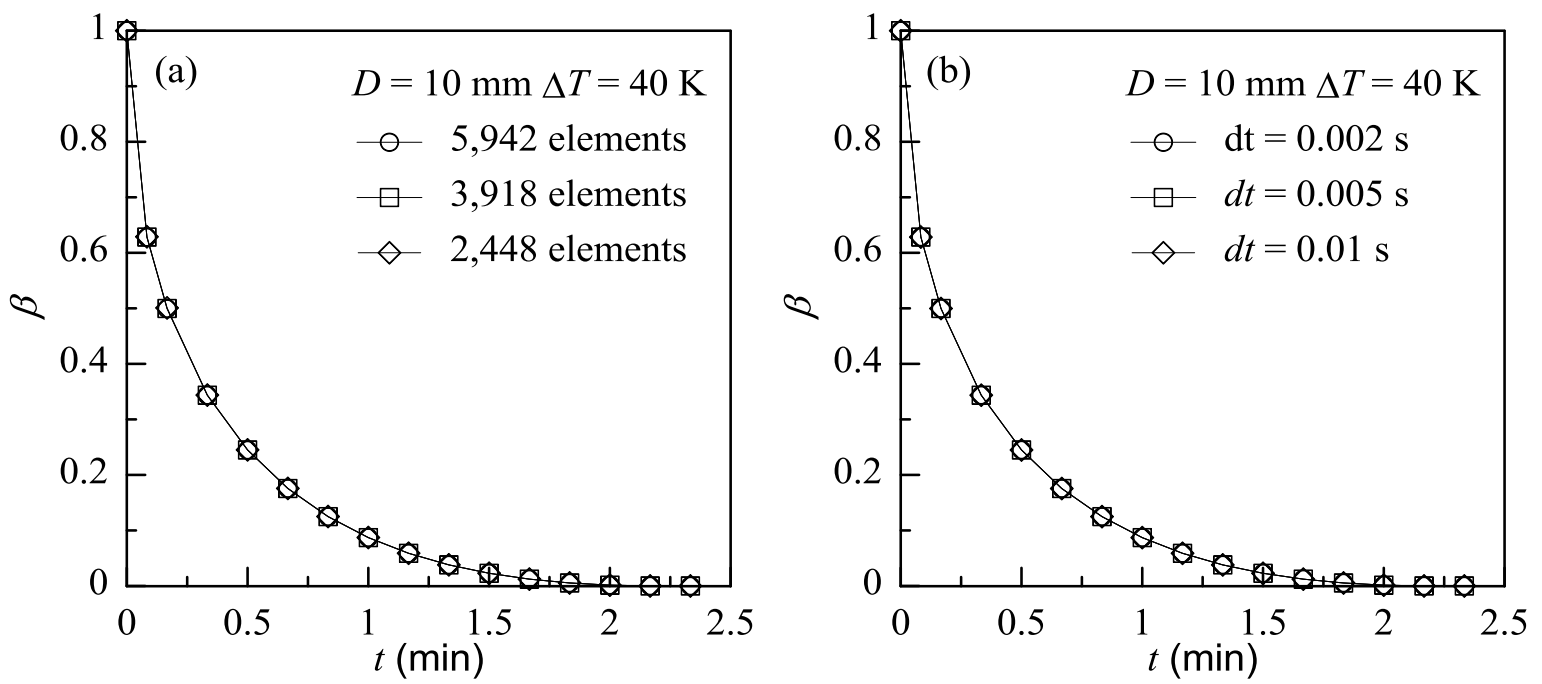

Figure 3 - Results of $\beta$ vs. $t$ for $D=10 \mathrm{~mm}$ and $\Delta \mathrm{T}=40 \mathrm{~K}$ : (a) spatial discretization test and (b) time discretization test. 


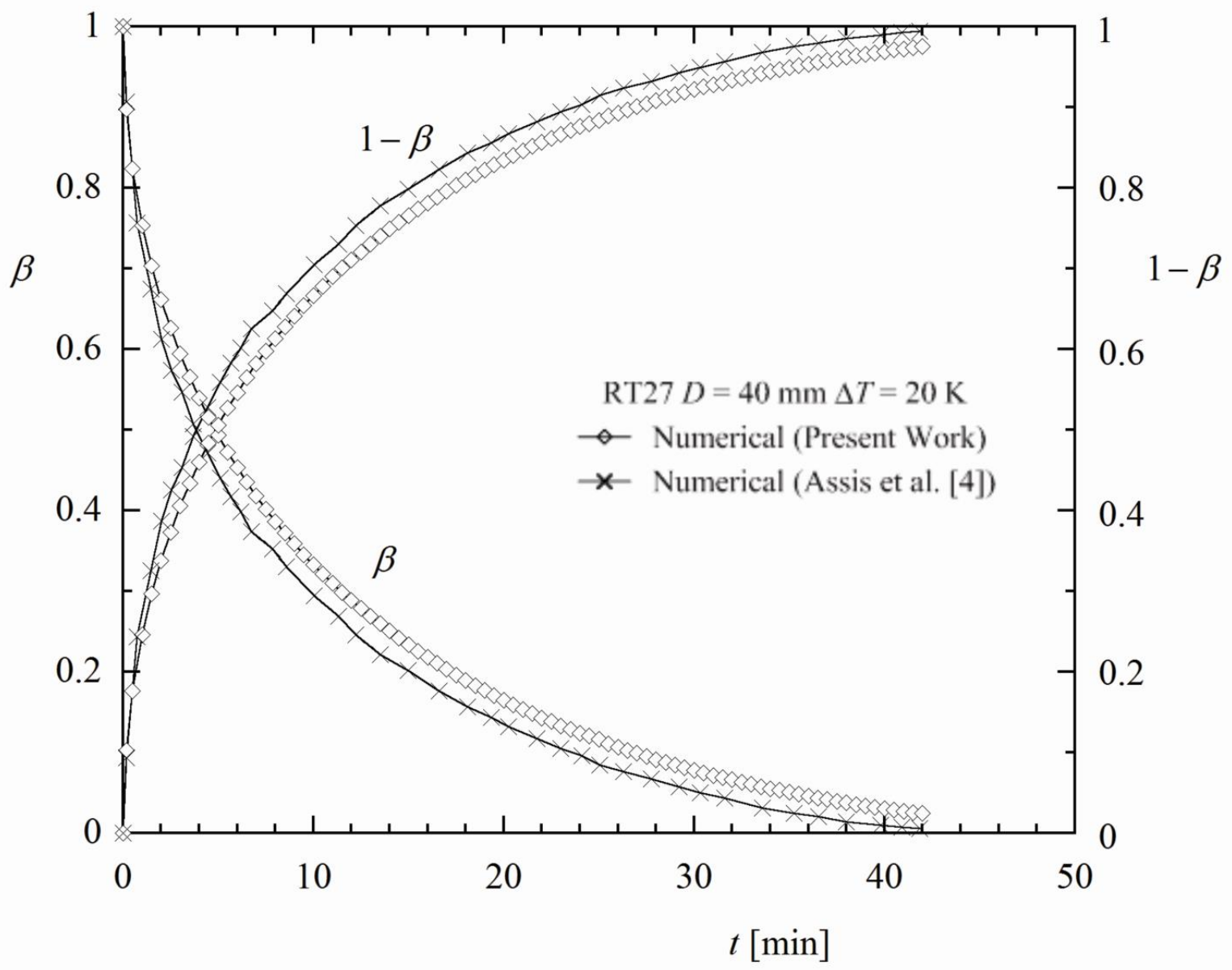

Figure 4 - Curves of the present work and Assis et al. [4] for liquid $(\beta)$ and solid (1- $\beta$ ) fractions as function of time for sphere of $D=40 \mathrm{~mm}$ and $\Delta T=20 \mathrm{~K}$ with RT27, 


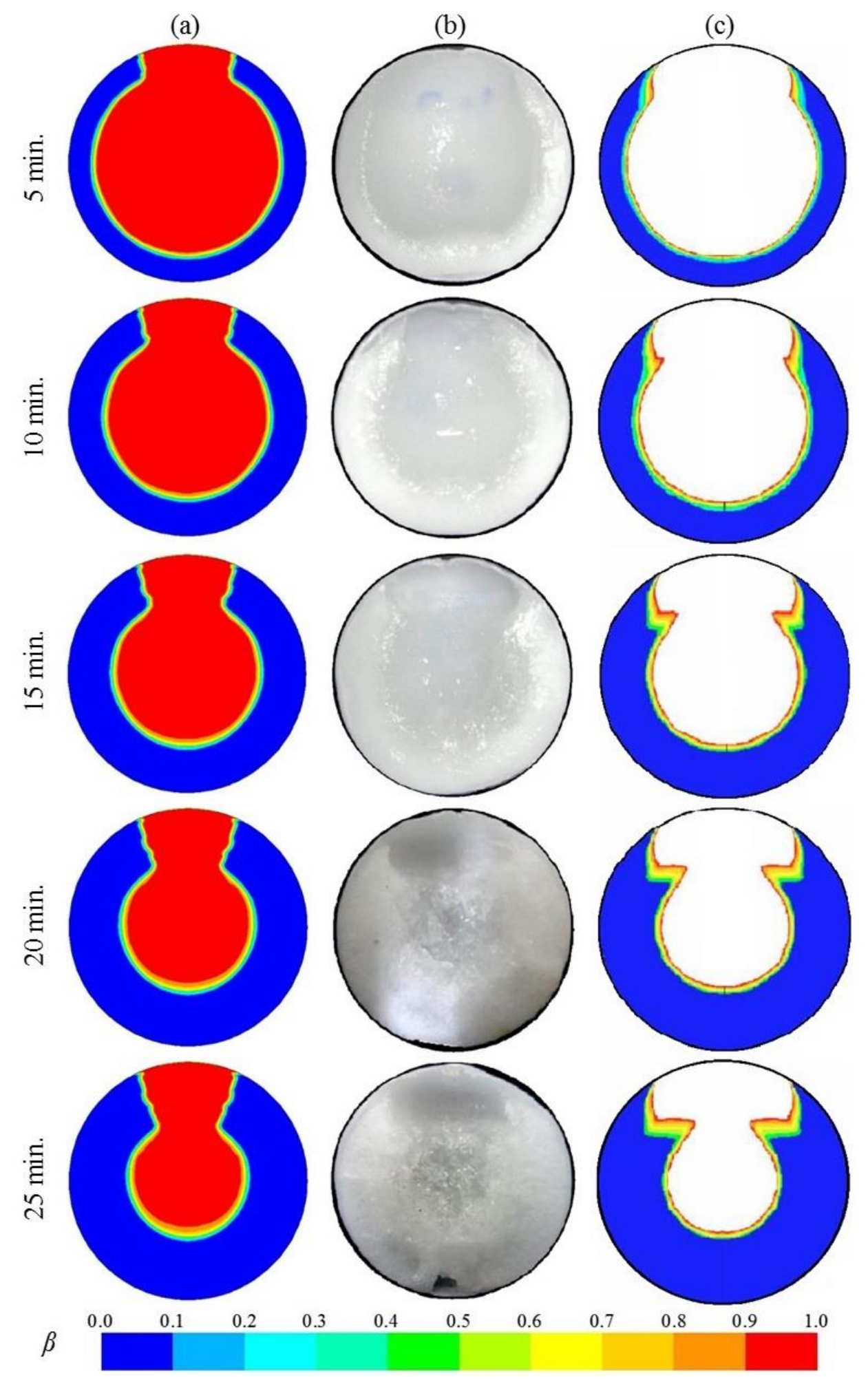


Figure 5 - Liquid fraction contours of RT27 in $t=5,10,15,20$ and 25 min, for: (a) present work, (b) experimental (Assis et al. [4]) and (c) numerical (Assis et al. [4]).
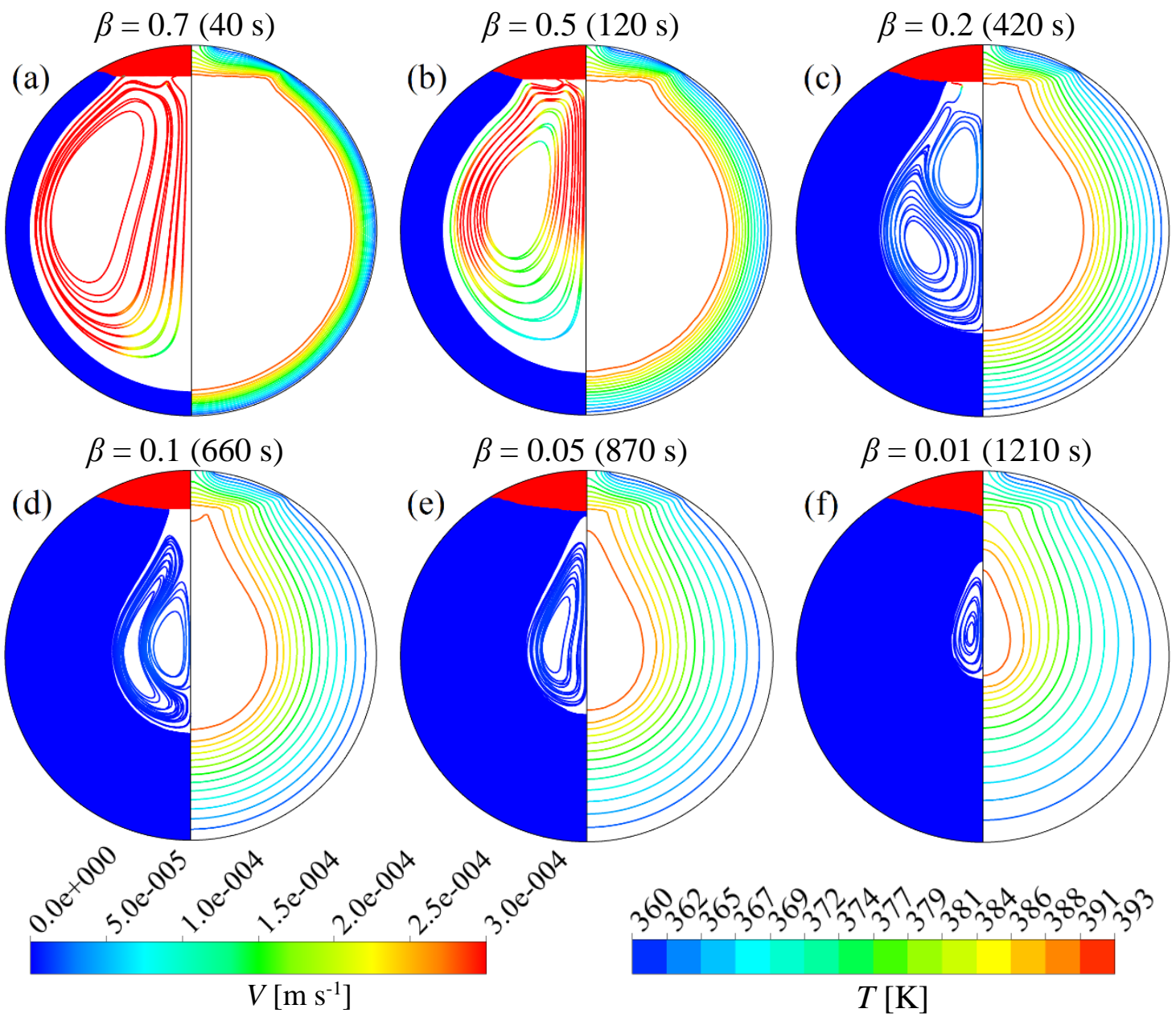

Figure 6 - Streamlines in the liquid PCM and temperature lines in the solid PCM, for $D=$ $30 \mathrm{~mm}$ and $\Delta T=30 \mathrm{~K}$ : (a) $\beta=0.7$; (b) $\beta=0.5$; (c) $\beta=0.2$; (d) $\beta=0.1$; (e) $\beta=0.05$ and (f) $\beta=0.01$. 


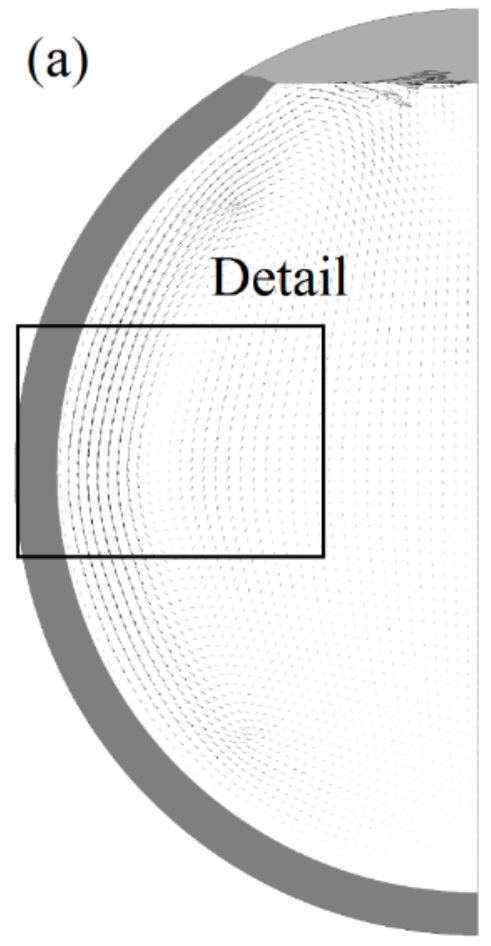

(b)

\section{Detail}

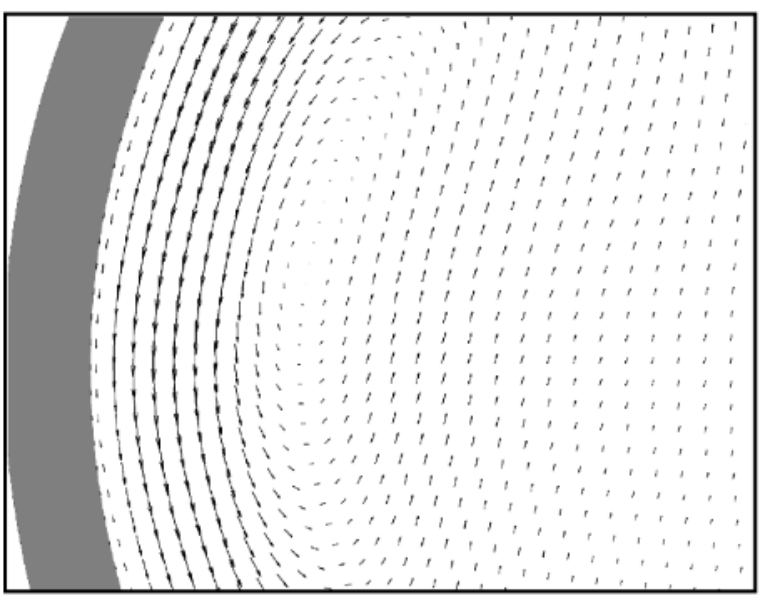

Figure 7 - Velocity vectors for $D=40 \mathrm{~mm}$ and $\Delta T=40 \mathrm{~K}$ at $0.5 \mathrm{~min}$ : (a) integral and (b) detail. 

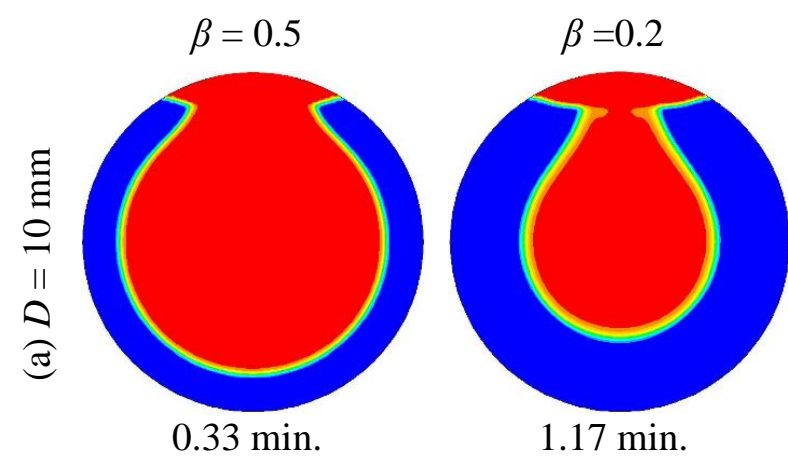

$1.17 \mathrm{~min}$.
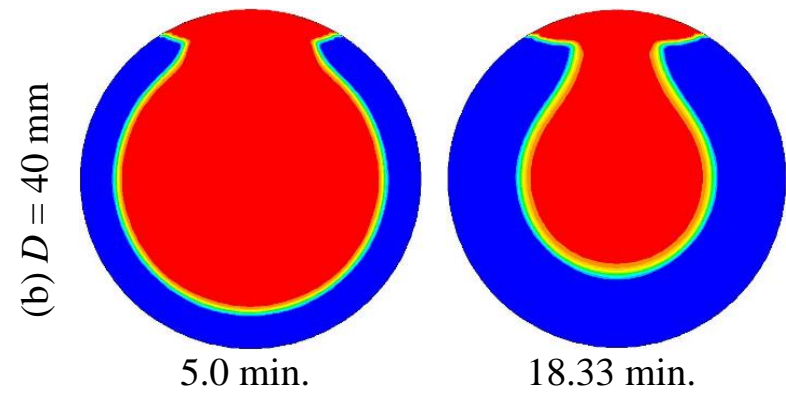

$18.33 \mathrm{~min}$.

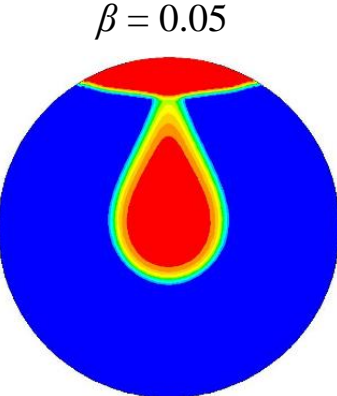

$2.5 \mathrm{~min}$.

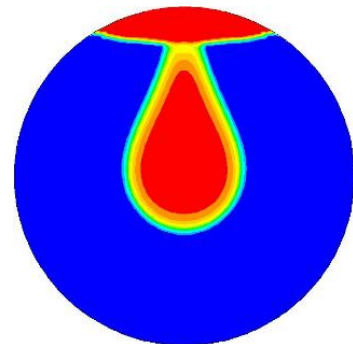

38.33 min.

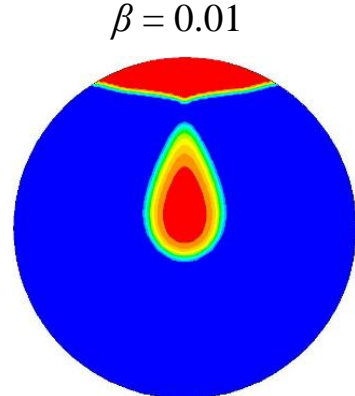

$3.17 \mathrm{~min}$.

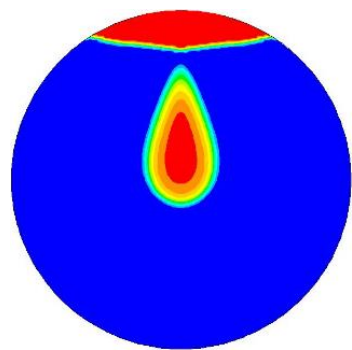

$51.67 \mathrm{~min}$.

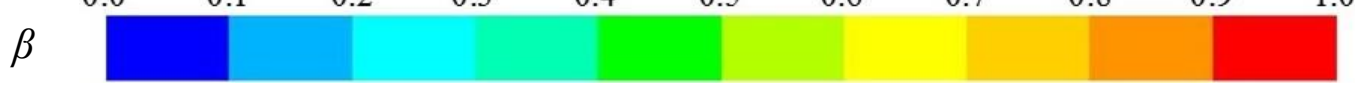

Figure 8 - Contours of liquid fraction of erythritol along the solidification process with $\Delta T$ $=20 \mathrm{~K}$, for (a) $D=10 \mathrm{~mm}$, (b) $D=20 \mathrm{~mm}$, (c) $D=30 \mathrm{~mm}$ and (d) $D=40 \mathrm{~mm}$. 

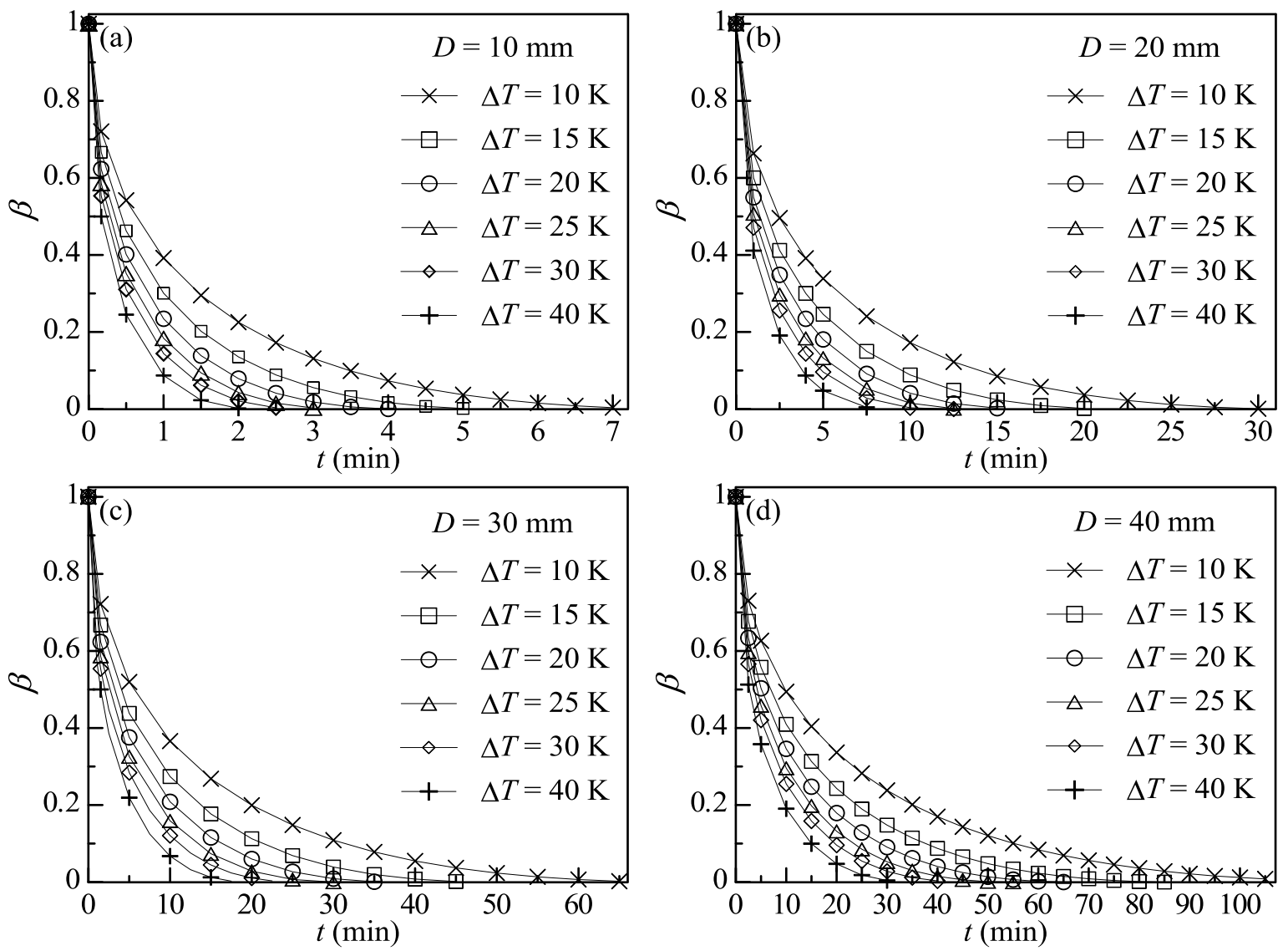

Figure $9-\beta$ vs. $t$, with $\Delta T=10,15,20,25,30$ and $40 \mathrm{~K}$, for $D$ of: (a) $10 \mathrm{~mm}$, (b) $20 \mathrm{~mm}$, (c) $30 \mathrm{~mm}$ and (d) $40 \mathrm{~mm}$. 


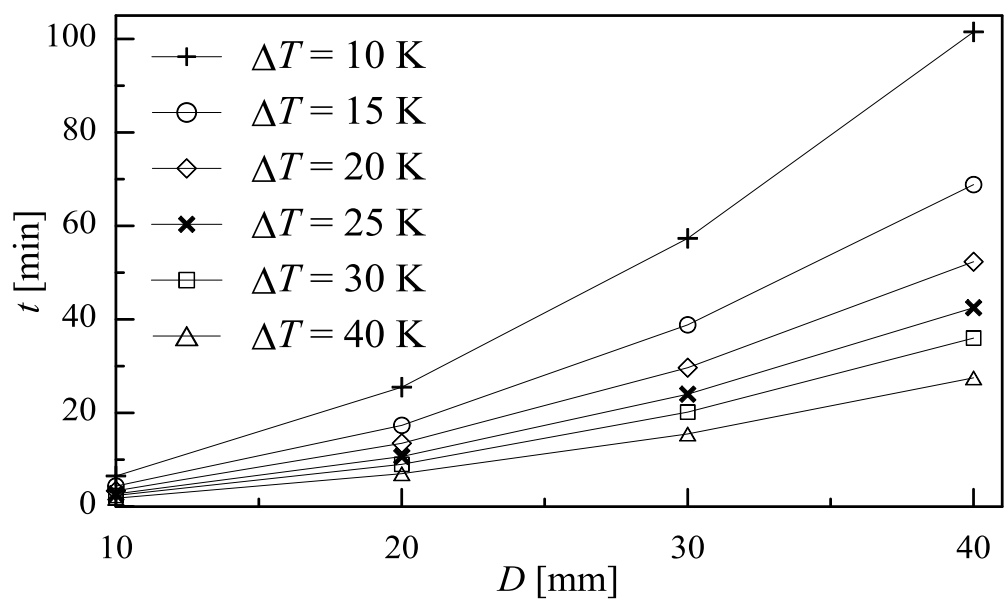

Figure 10 - Total solidification time vs. $D$. 

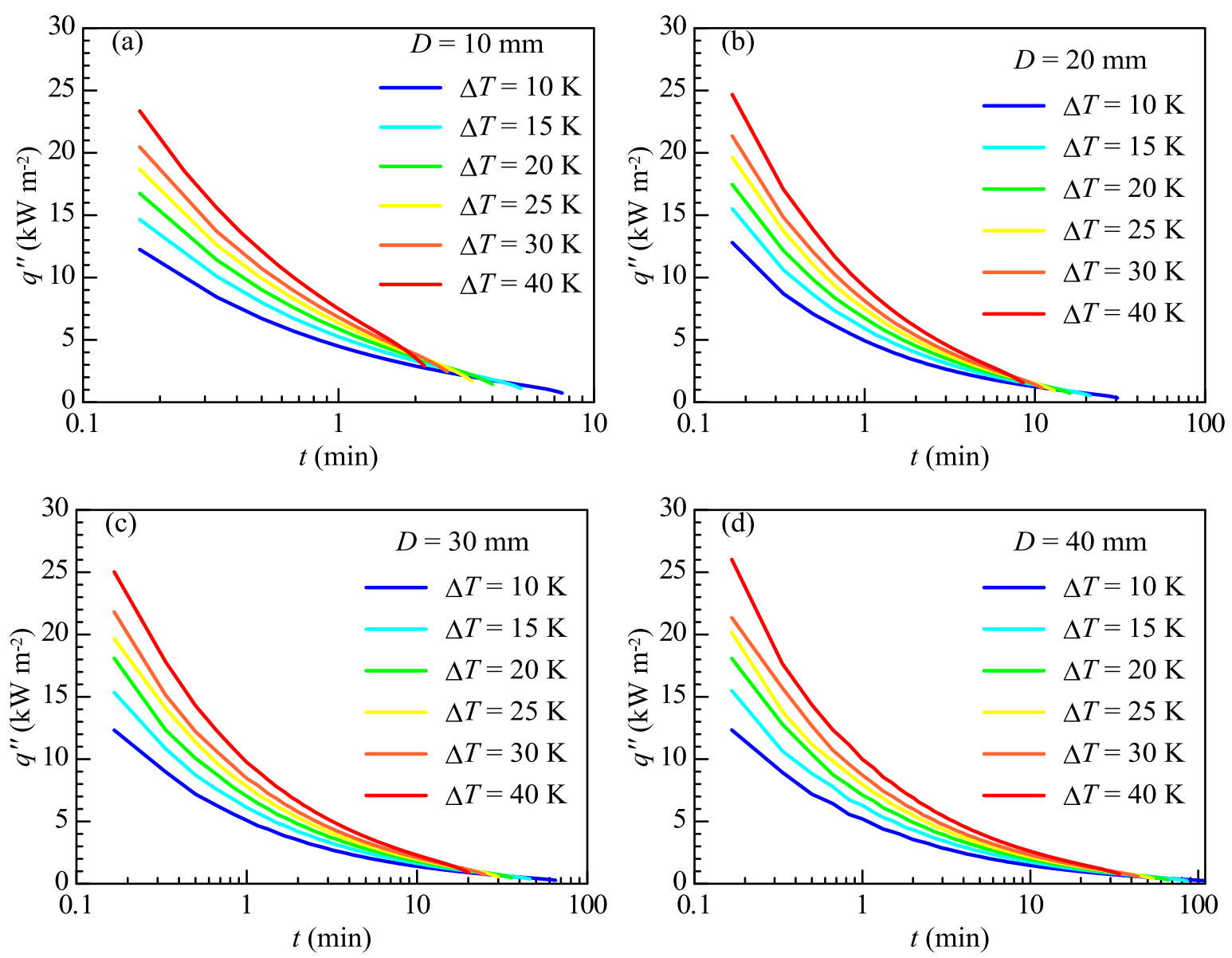

Figure $11-q$ " vs. $t$, with $\Delta T=10,15,20,25,30$ and $40 \mathrm{~K}$, for $D$ of: (a) $10 \mathrm{~mm}$, (b) $20 \mathrm{~mm}$, (c) $30 \mathrm{~mm}$ and (d) $40 \mathrm{~mm}$. 


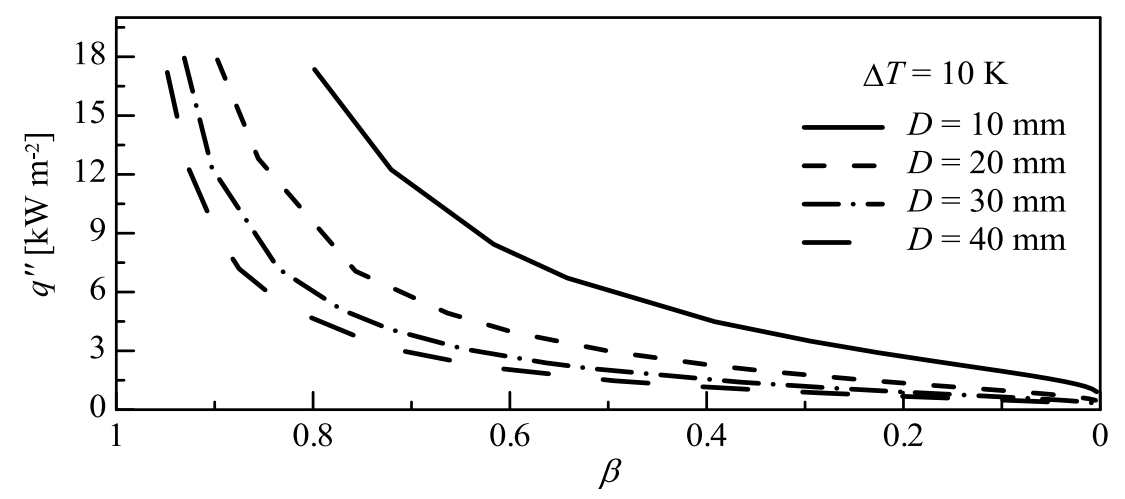

Figure $12-q$ " vs. $\beta$ with $\Delta T=10 \mathrm{~K}$ for $D=10,20,30$ and $40 \mathrm{~mm}$. 


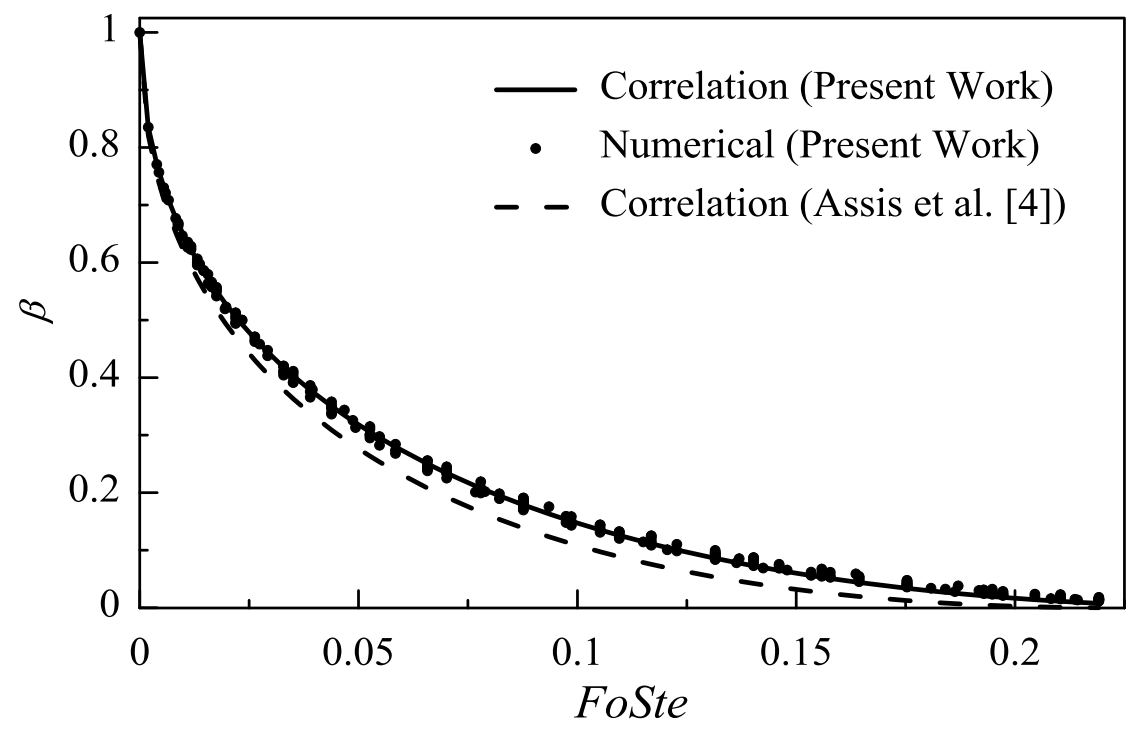

Figure 13- $\beta$ vs. Fo and Ste product, for the cases numerically analyzed and for the correlations of Assis et al. [4] and the one adjusted at the present work. 


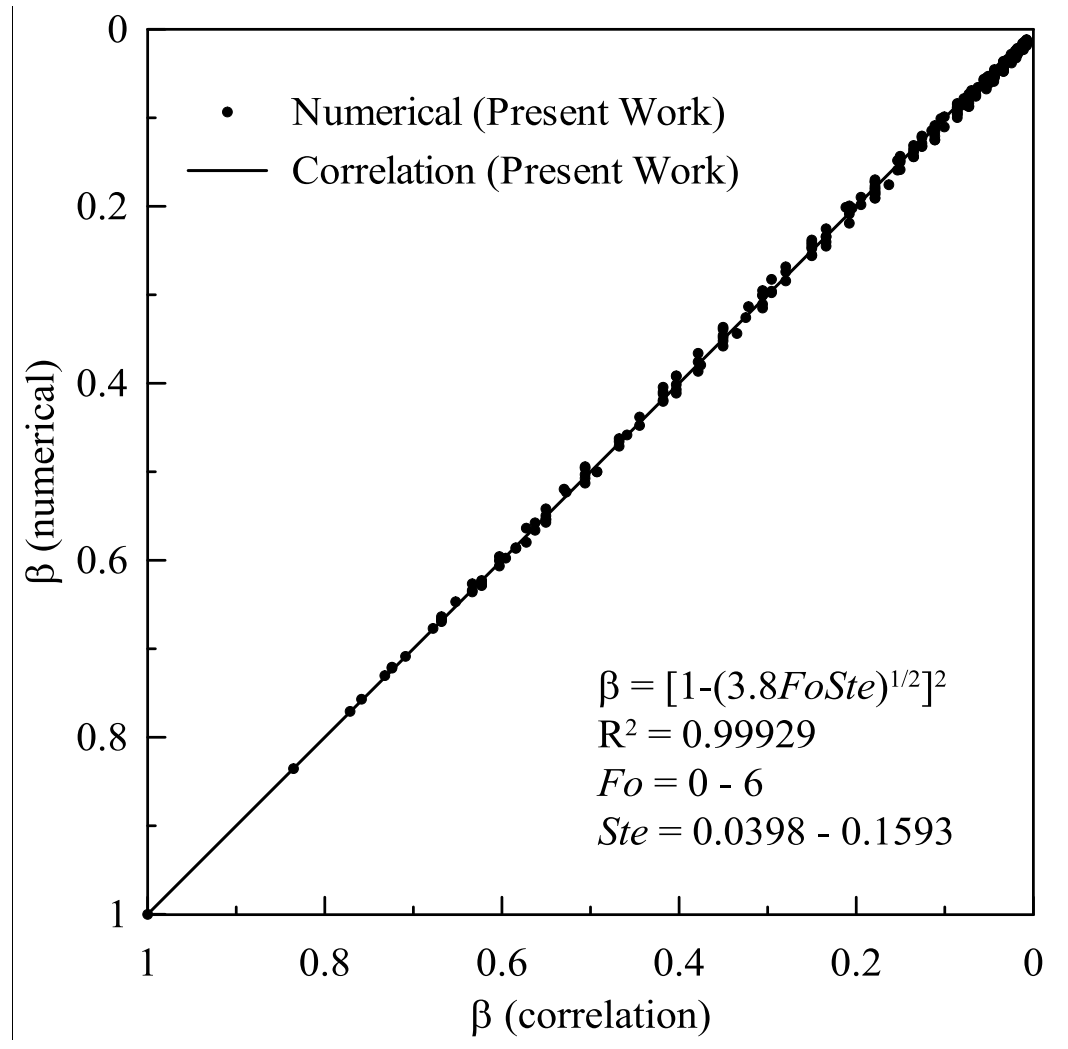

Figure $14-\beta$ of the numerical results vs $\beta$ of the modified correlation. 